\title{
Hurricane Katrina and the Health System: Lessons Learned
}

Frederick P. Cerise, MD, MPH

$\mathrm{T}$ The assumption that the United States has a health care system that is organized to ensure health care for the population is an erroneous one. In reality, there is relatively little true organization within the health care sector, which consists of a large number of independent businesses with missions that range from charitable to entrepreneurial. Even the not-for-profit businesses must compete with their for-profit counterparts, and therefore their business practices are often similar. It is a highly lucrative and competitive industry, and fragmentation and disorganization historically have been good for business.

Fragmentation, disorganization, and competition balanced with public programs to fill the gaps may work in a stable environment, but they are not the best ingredients to address the problem of access to care in a region with limited resources in the wake of a natural disaster. Although the majority of health care provided in the United States is funded with public dollars, ${ }^{1}$ we as a nation remain reluctant to impose public requirements or organization on that sector, even after a disaster.

Post-Katrina, providers began positioning early. Health care is a competitive business and providers are forced to respond strategically, not to think charitably about their approaches to a major disruption in the status quo. Many mobile providers such as doctors and nurses left the region when the population dispersed. Fixed providers such as hospitals either closed or sought to improve their positions in the marketplace. Amid potential large scale reorganization, the actions of public officials and private individuals and businesses provided a number of lessons in the months and years following Hurricane Katrina, some of which are enumerated in the following paragraphs.

Although crises can provide opportunities for reform, the midst of a disaster is not the best time to address long-standing, complex, systemic problems. Surveying the field hospital in Baton Rouge within a week of Katrina, Centers for Medicare \& Medicaid Services Administrator Mark McClelland and I agreed that the New Orleans hospital industry was over bedded before the storm. Katrina corrected that statistic, but it did not change the underlying reasons why the city was over bedded. It was over bedded compared to other cities because Louisiana abandoned its Certificate of Need (CON) program 20 years before Katrina hit, whereas two thirds of states continue to have CONs, and there was a sufficient level of private and public health care coverage in the community with a sufficiently fragmented delivery system and reimbursement structure to support high use rates among insured individuals. It was not over bedded because of the high uninsured population. Nineteen percent of the state's population was uninsured and this group accounted for $6.7 \%$ of health care spending. ${ }^{2}$ Many advocated then and continue to erroneously advocate that the solution to over bedding is to restrict health care access for uninsured people.

In the months after Katrina, Health and Human Services Secretary Michael Leavitt, in an attempt to take advantage of a "greenfield" in the health care delivery system in New Orleans, proposed widespread redesign of the New Orleans health care industry in a manner consistent with his bent toward a private insurance model but inconsistent with state and federal health care rules, which are difficult to change under stable circumstances. Furthermore, his assumptions were inconsistent with the economic reality that the state could not insure the entire uninsured population in the New Orleans region without additional dollars. ${ }^{3}$ After many months and thousands of man hours working on a reform model for the city that ultimately state and federal officials could not deliver without substantial legislative action, including additional appropriations, the effort to reach agreement among multiple competing private health care providers and public officials to design a new health care delivery system for New Orleans failed. It took a shift in power in Congress to prompt hearings that ultimately led to the release of hundreds of millions of dollars in recovery funds that Congress had appropriated but which the Secretary was holding as a carrot for reform.

As reinforced by the recent health care reform debates, our society has a collective cognitive dissonance between our desire to ensure health care for everyone and our unwillingness to enact public policies to ensure health care for everyone. In the weeks and months after Katrina, there was ongoing competition among health care providers. Because so much housing had been destroyed and hundreds of thousands of people were displaced from the city, the hospitals that remained open were competing with each other for the scarce number of remaining workers. In addition, hospitals needed doctors on staff to admit and care for patients. State officials were approached by several people who were concerned that closed hospitals would reopen offering only elective services and no emergency departments (EDs) as a strategy to better control their business mix. This would have put great strain on those hospitals with EDs, which risked losing nurses and doctors whom, it was feared, would have moved to the newly opened hospitals without the EDs, thereby limiting their exposure to on-call coverage for uninsured patients. 
In response, the state Department of Health and Hospitals worked with the chair of Louisiana's House Health and Welfare Committee to develop CON legislation that would have required analysis and approval of additional services for a 3-year period in an attempt to create some order around the return of services. That proposed legislation did not survive the first discussion with representatives of the hospitals in the city and was never filed.

We have unrealistic expectations that private business competitors in markets, which are not concerned with equity, will act from a perspective of the larger societal interest. There is no market principle that would predict such behavior. This is not to say that many people and companies did not provide extraordinary services during Katrina; but we cannot expect that these businesses are going to fundamentally change their practices in response to broader societal needs. In the midst of crisis, they must remain concerned about their businesses.

In the months following Katrina, public and private individuals grappled with identifying resources such as health care providers and space to provide needed services. Areas of great need included the relatively low-tech primary care and psychiatric services. Instead, one large health system was bringing back transplant programs, clearly a priority for that system's business but not for the population. Despite attempts by the state to pay the full costs of services for any uninsured inpatient psychiatric care, no providers were willing to open those services.

There is a balancing act between supporting local businesses and meeting the needs of the citizenry, and this creates tensions between the local workforce and relief workers from out of town. The ideal scenario for recovery would consist of local people receiving the necessary support to provide needed services, bridging them economically while they meet the local needs. Unfortunately, it often does not work out that neatly, and the considerations of local businesses and their resistance to "competition" from outside assistance can result in a reduction in services available to the people in need. When this happens, the needs of the patients become secondary to the needs of the provider. Unless there is some special local expertise (eg, local fishermen who know the marshland affected by the BP oil spill better than out-of-state contractors), particularly in the immediate aftermath, it is more predictable to rely upon imported, prepared, emergency response teams and transition those services to volunteers and local providers as soon as it is feasible to do so.

Post-Katrina, Louisiana received grant funds to recruit and retain a health care workforce. Unfortunately, grants to retain workers are likely to be inefficient because they do not differentiate between those who are considering leaving and those who are not, particularly when they come many months and even years into recovery as they did for Katrina survivors, when much of the resettling had already occurred.
Finally, leaders do and should take advantage of the disruption created by crises to accelerate needed changes during recovery. Many people expressed shock about comments made by President Obama's chief of staff, Rahm Emanuel, during the financial crisis/recession beginning in late 2007 and which has received renewed attention in the aftermath of the BP oil spill: "You never let a serious crisis go to waste. And what I mean by that it's an opportunity to do things you think you could not do before." The fact is, serious leaders will always act in such a fashion. Federal, state, and local education leaders used Katrina as an opportunity to reform a troubled school system in New Orleans. Housing officials used the crisis to reform publicly subsidized housing in New Orleans. And state and Louisiana State University (LSU) officials used it an opportunity to reform the public hospital system in New Orleans.

The present population in the New Orleans region is 789000 , about $81 \%$ of the population pre-Katrina. Three area hospitals, which accounted for $17 \%$ of the market pre-Katrina, remain closed. In addition, Charity Hospital in New Orleans, which accounted for another $13 \%$, remains closed and LSU is operating the public hospital and clinics out of interim facilities. Before Katrina, the Charity complex operated 550 beds. Presently, the interim hospital is operating 283 beds, including 38 psychiatric beds, which is less than half of what was operated before Katrina, and those beds remain 99\% occupied. The hospital accommodates about half of the inpatient volume compared to pre-Katrina rates and runs a gamut of primary care and specialty clinics out of an old department store. The system accounts for more than 280000 clinic and ED visits, about $80 \%$ of the outpatient volume compared to that before Katrina.

Historically, $70 \%$ of the physician workforce in Louisiana trained in an LSU program or in an LSU hospital. Sixty-three of 64 parishes in the state are designated as health professions shortage areas, and this is before the predictable increased demand to be generated by the federal coverage expansions. More than $63 \%$ of the indigent and self-pay population in the area was served at Charity Hospital for inpatient care, and Charity Hospital served as a statewide referral center for trauma and other specialty care for uninsured people. A much larger percentage relied upon the Charity clinics for outpatient care. Before Katrina, Charity Hospital trained the largest number of medical residents in the state, with more than 500 residents plus hundreds of nursing and allied health students training there.

Within 1 year of Katrina, the state appropriated $\$ 300$ million toward the replacement of the old Charity Hospital, and after $41 / 2$ years finally received a judgment acknowledging that the facility was destroyed and ordering FEMA to pay $\$ 474$ million for a replacement. FEMA was clearly overwhelmed by this largescale disaster and its processes resulted in long delays not only for this project but also many others. 
Louisiana governor Bobby Jindal has continued support for a replacement hospital with the proviso that the new facility be managed by an LSU-affiliated, private not-for-profit corporation, an organizational transformation made by a number of public medical schools and their hospitals over the past 20 years. Opposition to rebuilding has come from many quarters, including preservationists and competitors, who benefitted from the old Charity operation that cared for the vast majority of uninsured patients but was not competitive outside that market. The resistance to this change has resulted in numerous delays. Still, planning for the replacement medical center to be built in conjunction with the replacement Veterans Affairs Medical Center is ongoing, with construction set to begin near the end of 2010 and completion expected in 2014.

Health care continues to confound us as we attempt to ensure universal access to care yet rely upon an uncoordinated market to provide that care. In a stable environment, health care is not viewed universally as a right for all to access equitably, but rather consists of a patchwork of private and public programs that have achieved some relatively functional steady state. It would be a mistake to expect that same sector to function smoothly as a system to provide a public service in the aftermath of a disaster. A crisis demands cooperation and coordination to optimize limited resources to meet a public need; however, the health care sector consists largely of disparate private providers in a competitive market in which the rules discourage collaboration.

There are no simple solutions to achieve the optimal response. At the risk of sounding trite, the best immediate re- sponse requires knowledgeable and fully engaged leaders with decision-making authority and excellent communication and cooperation at multiple levels of government and among volunteers and local providers. Leaders at all levels must share the common primary goal of stabilizing the population; this was not always present after Katrina, and it has made the recovery more difficult. Longer-term recovery requires strong and coordinated local and state leadership with a resilient and engaged citizenry.

Despite the many challenges and setbacks during the past 5 years, New Orleans is recovering and, amazingly, remains optimistic.

Author Affiliations: Dr Cerise was Secretary, Louisiana Department of Health and Hospitals during Hurricane Katrina and currently is Vice President for Health Affairs and Education, Louisiana State University System.

Correspondence: Address correspondence and reprint requests to Frederick P. Cerise, 3810 West Lakeshore Drive, Baton Rouge, LA 70808 (e-mail: fcerise @1su.edu).

Received for publication: June 28, 2010; accepted July 20, 2010.

Author's Disclosure: The author reports no conflict of interest.

\section{REFERENCES}

1. Seldon TM, Sing M. The distribution of public spending for health care in the United States, 2002. Health Aff (Millwood). 2008;27(5):w349-w359.

2. Price Waterhouse Coopers. Report on Louisiana Healthcare Delivery and Financing System. Louisiana Recovery Authority Web site. http://lra .louisiana.gov/assets/docs/searchable/reports/PwChealthcarereport427061 .pdf. Accessed June 27, 2010.

3. Zuckerman S, Hadley J. Louisiana's proposed section 1115 waiver Medicaid demonstration project: estimating the numbers of uninsured and projected Medicaid costs. Kaiser Family Foundation Web site. http://www.kff .org/uninsured/7669.cfm. Updated July 16, 2007. Accessed June 27, 2010. 